\title{
Continuous Professional Development for Novice Teachers of English
}

\author{
Bülent Alan \\ Anadolu University, Eskişehir, Turkey
}

\begin{abstract}
Novice language teachers, especially those who are in their first or second year of teaching, generally feel a need for in-service programs that better equip them for the institutional needs, expectations, and challenges, as well as meeting their own professional development agenda. Although most educational institutions have their own induction and in-service programs, most of these programs are pre-planned or set programs addressing the institutional needs and may not always meet the individual needs of the novice teachers. Therefore, novice teachers may feel in despair and search for ways to develop themselves professionally, academically, as well as personally. In recent years, continuous professional development (CPD) programs are in rise and many educational institutions now have started to establish their own CPD programs to meet the needs of all of their teachers, especially those who are relatively new to the profession. In accordance with the new changes and trends, Anadolu University (a state university in Turkey) School of Foreign Languages (AUSFL) initiated a new CPD program for its teachers. In this paper, the preliminary findings, namely, findings from the needs of novice teachers are presented. In part of the needs assessment, novice teachers' needs and expectations from a CPD program are sought and based on their responses, a new, institutional model is proposed.
\end{abstract}

Keywords: in-service training, continuous professional development (CPD), novice teachers

\section{Introduction}

As part of its teacher development program, an in-service teacher training (INSET) program was implemented at Anadolu University School of Foreign Languages (AUSFL) in the 2002-2003 academic year. The researcher conducted a study regarding the usefulness of INSET courses for the participants. Seventeen novice teachers who were in their first year of teaching participated in INSET courses at AUSFL. The aim of the study was to explore the novice teachers' perceptions of these INSET courses. The study had revealed that the factors affecting the usefulness of INSET courses were:

(a) Amount of contextual relevance of the knowledge presented;

(b) Timing of the workshops;

(c) Amount of reflection and participation allowed in training sessions.

Again as part of its professional development program, AUSFL carried out an INSET program for its eight newly recruited novice teachers in 2014. The purpose of the study is to compare the results of these two studies to provide an institutional INSET model and give some insights for the institutions planning to hold INSET programs especially for novice teachers.

Bülent Alan, M.A., Ph.D. candidate, instructor, School of Foreign Languages, Anadolu Universtity. 


\section{Method}

\section{Participants}

Novice teachers have been defined as those who have three or fewer years of teaching experience (Freeman, 2001). However, Anadolu University regards novice teachers as those who are in their first year of teaching. The study was conducted with eight novice English teachers of AUSFL in 2013-2014. The teachers were in their first year of teaching. Six of the participants have a Bachelor of Arts (B.A.) degree in teaching English as a foreign language (TEFL), one of them has BA in English language and literature, and one participant has BA in translation. Only two of them had some previous teaching experience at different schools which are completely different from AUSFL. Participation for this INSET program was obligatory for these novice teachers.

\section{Setting}

The study was conducted in AUSFL, Eskişehir, Turkey. AUSFL provides one-year intensive English, German, and French language education before students pass their departments for content education. There are almost 150 English instructors and 2,800 English language learners at AUSFL.

\section{Procedure}

The INSET program lasted almost four months. The first month of the training was just before the beginning of the semester and the participants had both theoretical and practical training on their subject matter and the institution in which they teach. Their training included academic readings and discussions as well. The rest of the training continued while they were teaching at AUSFL. During this part of the INSET program, the trainees (the novice teachers) participated in seminars which were conducted once a week. The participants observed their trainers and other experienced teachers working in their school. They were also observed by their trainers and peers. In addition to the observations, they video-recorded their lessons and evaluated their performance with their trainers and peers.

\section{Instruments}

Two research instruments were used in this study:

(a) A survey consisting of 11 questions;

(b) Semi-structured interviews with randomly chosen participants.

\section{Data Analysis}

Qualitative data analysis procedure was used by the researcher. After the survey was collected, participants' responses were analysed based on the interpretations of patterns emerging from their responses. The second step in data analysis was the interpretation of the interviews. The interviews were transcribed and emerging themes were highlighted.

\section{Findings}

While analyzing the open-ended questions in the survey, the researcher identified three categories which emerged from participants' entries.

\section{Practical Applications and Reflections of the Program}

The participants mentioned that some of the knowledge and practice they gained from the INSET program had an immediate impact on both the way they feel in their new institution and on their teaching. This helped 
them overcome their anxiety in their first year of teaching and put them at ease. Especially the orientation part of the program helped them a lot in getting familiar with their institution and with their new roles and responsibilities. Below you can see some responses regarding this theme.

Novice teachers can have a chance to observe and learn the system applied at this institution. It could help them in terms of adapting themselves to the environment. (Participant 5)

It was very helpful in adjusting to the new work place and surroundings. It helped me break the tension I had at that time. (Participant 6)

Starting with the orientation part, it was necessary and $80 \%$ useful because we had a chance to get to know the units, unit responsibilities, and their role at the school. (Participant 7)

Lesson observation was the most efficient way of finding out the system in a new institution. (Participant 2)

Because I learned many things about the curriculum and assessment system in our institution. (Participant 1)

Some responses of the participants showed the immediate impact of the program on their teaching practices. Classroom observations, getting advice from the trainers and experienced teachers, and self-evaluations and reflections helped novice teachers either gain new methods and techniques or some practical ideas about the issues they had limited knowledge or no experience. The responses below support this:

I took my trainers' and friends' advice into consideration. (Participant 5)

The advice of the experienced teachers I observed and our trainers helped me see my strengths and weaknesses. I mostly changed my methods of grouping students in the classroom and giving feedback. (Participant 7)

Because I obtained some novel ideas and some "do's and don'ts" in terms of specially classroom management and lead-in activities. Realizing what I did and what I can or should do for a better, more fun, and versatile education both for me and students. (Participant 1)

Alan's (2003) study had already revealed that participants found the INSET workshops the most valuable when the knowledge presented during these INSET courses were contextual and addressed the immediate needs of the participants. This study also revealed similar results regarding the content of the workshops and courses presented during the program. Therefore, an INSET or professional development program should keep in mind that every institution is unique in terms of students, available resources, and requirements, so the programs should be designed on an institutional basis which will equip the participants with the relevant and urgent practical knowledge. This may help participants who are especially novice teachers feel comfortable and confident when they start teaching in an environment which is unfamiliar to them with their new roles as teachers. In addition, when the participants do not find practical knowledge or feel a mismatch between what has been presented during the INSET program and what they have been actually doing in their teaching may hinder their faith in the usefulness of such professional development programs that will be held in the future (Alan, 2003), or their negative attitudes and experiences might negatively affect the attitudes of prospective novice teachers who will start teaching in the following years in the same institution. Below you can see some negative responses regarding irrelevant data:

The only thing which was inefficient was that our trainers made us read some books about Common European Framework for References (CEFR), which did not work for us. (Participant 5)

In terms of knowledge in field, I cannot say it helped a lot. We did not specifically focus on local requirements or goals. It was for general professional development. (Participant 6)

I do not think it was localized. It could work well for any prep school because it did not aim at any special difficulties, such as outcomes of CEFR, special student profile of our school, etc.. (Participant 5) 
Apart from their responses to the survey, the interviews also revealed that some knowledge they gained from the INSET program, such as how to assess and give feedback to written assignments and how to conduct speaking exams and marking portfolios, was totally new for them. They confessed that it would have been unfair for the students if they had started practicing these without taking any specific training.

\section{Timing}

Another emerged theme mostly stated by the participants was timing. Having limited time after lessons to pursue a professional development program was a challenge for the novice teachers. Their heavy workload in a tight schedule did not allow them to fulfil the necessary requirements of the program. Below you can see how these novice teachers expressed their views regarding lacking time:

We had 24 class hours a week and we used to spend a lot of time preparing for the lessons, so we could not concentrate on our in-service training course. (Participant 7)

It was during the academic semester so both for the trainers and trainees it was difficult to get together systematically. (Participant 1)

At a time when we did not have much time. (Participant 3)

It could have been enough, but under the intense working conditions of AUSFL, it was not. (Participant 7)

Twenty-four hours of lesson in a week the first time you are giving lessons. The time given to each practice was not enough although the practice was valuable in itself. (Participant 3)

I do not think it was enough. Four months would have been enough if we-novice teachers- had not had so many lesson hours in a week. Then we could have spent much time for in-service training instead of just one day a week. (Participant 4)

... But I had difficulties in managing all my lesson preparations, portfolio evaluations, doing research on my area, and the weekly in-service training meetings at the same time. So, I think we needed more time for more effective training. (Participant 2)

Because of the heavy teaching load as I mentioned before, we could not work through all teaching contents, such as teaching writing, lesson stages, and different methods for different learners. (Participant 4)

The responses of the participants suggest that novice teachers especially the ones who are participating in an INSET program should have a light schedule in order to make the best of these professional development programs. The participants stated that they did not have time to internalize the knowledge presented to them. They also had difficulties to cope with the requirements of the program while teaching intensively at the same time. This prevented them from applying some of the methods, ideas, or knowledge covered in the program since they did not have enough time to prepare their lessons in the light of course content. As a result of this, they felt that the program content sometimes was superficial, and they did not have time to discuss and apply the knowledge they gained in depth. When they do not apply and see the benefits of the knowledge presented in the program, it is really difficult to convince them in the usefulness of such professional development programs.

So, an INSET program for novice teachers must be conducted in a context where they have a light schedule. Their timetables should enable them to concentrate on their requirements for the INSET program. Besides, because they are not experienced and not accustomed to their new roles, they may not fulfil their responsibilities in terms of teaching and this will create other problems. Participants' interviews also supported their views. They stated that novice teachers should not have many lessons and should not have many responsibilities in their first year of teaching along with the INSET courses they take. They also added that they should not teach at all for a while if possible. 


\section{Classroom Observations and Recordings}

Participants' responses revealed that observation sessions were an important component of the training program. Almost all participants mentioned about the impact of observations both on their perceptions of the program and on their teaching practices. However, participants' responses were half positive and half negative. Therefore, the researcher further analyzed the reasons of this contradicting data through interviews which will be discussed later. Below are the samples of positive views regarding observations and how they influenced their teaching practice:

Specially, video-recording part with post-revision and criticism from trainers and trainees were beneficial for me. (Participant 1)

The more we observed, the more secure we felt about our upcoming classes. We should have done more observations. (Participant 3)

Also, via video-recording part, I had a chance to have an everlasting proof or phase that I can see and think on it. (Participant 1)

The only positive side for me was the observation parts where I could take one good thing from one teacher and another from another teacher. (Participant 3)

I believe lesson observation was the most efficient way of finding out the system in a new institution. (Participant 2)

Interviews with the participants also supported their responses. When the researcher asked them what the most beneficial part of the program was, they expressed their content with the observations. They stated that they learned a lot from both their peers and the experienced teachers they observed. Participants in the interviews stated that they are still applying some methods they gained from observing other teachers.

The findings above complements Alan's (2003) study that novice teachers do not want to be passive listeners in the courses presented during INSET programs. They want to take active roles in the professional development programs where they can discuss the usefulness of the methods and techniques they gain in the reflection sessions. They want to express their thoughts and views about the proposed models.

Besides, novice teachers are eager to learn the experiences of experienced teachers on certain cases in the institution they teach. They want to be prepared to the situations they will likely to encounter. During the interviews, the participants stated that each of them could have been matched with a mentor teacher. Sometimes, they felt lost since they could not always find someone to help them around and they did not know what to do or who to consult in those situations. They added that if they had had an experienced mentor teacher who knew the institution very well, it would have been great help for them.

As part of observation process, the participants sometimes video-recorded their lessons and this created a tense and artificial environment in the classroom.

... But it caused a tense environment in the classroom. So, it was not a good way to observe the class in its regular way. (Participant 7)

Recording and afterward giving feedback session was total disaster since the students were nervous because of the camera in the class. (Participant 3)

Did not work-Students did not behave naturally or were nervous. (Participant 6)

Both the teacher and students did not behave normally while they were being recorded. Even good students did not want to talk in the classroom or students were not risk-takers and this reduced the class participation. One of the participants stated that sometimes he had to tell lies to his students:

One day I cheated my students. I said the video-recorder was off, but actually it was on and recording our lesson. We 
had a great lesson. (Participant 5)

Another participant stated that during those video-recording sessions, it was difficult for her to explain the purpose of video-recording. The students thought that the purpose of the recordings was to test the teacher's competency. She said that her students sometimes asked, "Teacher, are you new? Are they (administration) observing you because you are new or because of something else?".

She also stated that recordings influenced both the teacher's and students' performance negatively; therefore, did not serve the intended purpose. Instead, the participants stated that there could have been more observation sessions to become aware of what other teachers are doing and also to get feedback about their own teaching practices.

\section{Conclusions and Implementations}

The study revealed that the characteristics of novice teachers participated in this study are similar to the characteristics of the novice teachers who participated in the INSET program in 2002 at AUSFL. The findings suggest some considerations while holding an INSET program taking the needs and characteristics of novice teachers into account.

Both studies compared in this paper indicate that INSET programs should meet the immediate needs of novice teachers. First of all, an INSET program should make novice teachers become aware of their responsibilities and challenges they will have in their new institution. Therefore, it should equip them with the necessary knowledge and skills that will enable them to cope with those challenges. The teachers may come from different backgrounds with different experiences, skills, and views about teaching. Their pre-service education prepares them to their profession theoretically, but they lack practice, so an INSET program for novice teachers should focus on the areas they are unfamiliar with and should emphasize practical issues. Some of these teachers may have some teaching experience; however, each institution is different and has its own culture that differs it from others. Even some experienced teachers may have some difficulties adapting to their new work place. For this reason, the INSET program should address those issues that will facilitate their adaptation to their new school. In addition, studies show that participants value the knowledge presented during the professional development programs when it is relevant to the context they teach. They develop positive attitudes towards the professional development programs when they experience the practical applications and benefits of the knowledge they are taught. The teachers who had the most positive induction experiences were the ones who worked for the institutions where they had their own induction programs (Harrison, 2001; Wong, 2004).

The findings revealed that timing of the workshops or seminars in an INSET program is of great importance. To begin with, rather than overloading the participants with lots of knowledge, they should be trained at a time just before they use it (Alan, 2003). This will have two benefits. First, learning the theory and logic behind an implementation and practicing it successively will reinforce the knowledge presented and hence will increase the retention. Second, the trainees will feel confident and comfortable while applying it. For instance, the norming sessions on how to assess writing midterm papers were of great help for the novice teachers, and they stated that apart from doing it properly, it helped them overcome their anxiety since they had not had such a training in their pre-service education.

Another important consideration related to timing of an INSET program is that it should allow participants to digest the knowledge presented to them. In order to do this, they need a light schedule; otherwise, the 
knowledge presented to them seem to be superficial. The participants stated that just because they started to prepare their lesson and its requirements for the following day after the training sessions, they did not have time to internalize what they had studied. The participants felt a need for some extra time so that they could discuss the effectiveness of the new methods and approaches with their peers. Also, one of the characteristics of novice teachers is that they spend more time on lesson planning and material development (Richards, Li, \& Tang, 1998), which may prevent them from sparing time for other tasks or pursuing professional development activities. Therefore, it is better for novice teachers to have minimum teaching hours with less responsibilities in a context where they can have an opportunity to practice the knowledge they gain in INSET.

The third main theme emerged from the study is observations. Observations were viewed as one of the most beneficial elements of the INSET program. The participants stated that they had learned a lot from observing their trainers, other experienced teachers, and their peers. They especially liked the discussion sessions of the observations and video-recordings of their lessons. As they became more aware of what other teachers were doing through observations and video-recordings, they became more self-confident. This implementation also increased the collaboration among novice teachers and gave pave to sharing almost everything they prepared for their lessons. During the interviews, they said that they created a group in a social networking site and shared their lesson plans, materials, and games. They also discussed and shared their ideas concerning the lessons they did that day and made their self-evaluations.

Alan's (2003) study had already revealed that novice teachers prefer an INSET program in which they are treated as colleagues, but not trainees. Therefore, an INSET program should be designed on a collaborative basis among both trainers and trainees allowing them to share their experiences and benefit from each other (Alan, 2003; Burns \& Richards, 2009). Novice teachers are willing to listen to the case studies of experienced teachers and they want to learn how their trainers or other experienced teachers deal with the occurring problems specific to their institution. The data also showed that novice teachers wish to work with a mentor teacher who will provide continuous help and guidance. The novice teachers stated that they felt a need for an experienced teacher whom they can reach whenever they needed. Continuing support for novice teachers is particularly important. Novice teachers need mentoring programs to meet their instructional, professional, and personal needs through support, encouragement, and coaching (Alan, 2003; Hobson, Ashby, Malderez, \& Tomilson, 2009). Assigning efficient mentor teachers who can be good models for novices may help solve some of their problems. INSET trainers have essential roles as mentors for novice teachers.

As part of the observations, the novice teachers were asked to video-record their lessons; however, this implementation caused some problems and did not work for them as intended. The first drawback of video-recording was that the students did not behave naturally. As a result, what was watched and criticized during the reflection sessions of the lessons neither reflected the real picture of the classroom nor the real performance of the novice teachers. Another disadvantage of video-recording was students' misinterpretation about the implementation. The participants stated that their students had some misconceptions about their competencies. The students thought that their teachers were being observed by the administration and they were not qualified enough because they were new. This had a negative impact on the novice teachers' perceptions of the INSET program. The video-recordings were conducted in good purpose and most of the teachers benefited from them; however, the data suggest that it should be implemented carefully especially in contexts where students and teachers are not familiar with it. For this reason, both parties should be convinced of the usefulness and the real purpose of video-recording in the lesson. 


\section{References}

Alan, B. (2003). Novice teachers' perceptions of an in-service teacher training course at Anadolu University (Unpublished master's thesis, Bilkent University, Ankara).

Burns, A., \& Richards, J. C. (Eds.). (2009). Cambridge guide to second language teacher education. New York, N.Y.: Cambridge University Press.

Freeman, D. (2001). Second language teacher education. In R. Carter, \& D. Nunan (Eds.), The Cambridge guide to teaching English to speakers of other languages (pp. 72-79). Cambridge, U.K.: Cambridge University Press.

Harrison, J. K. (2001). The induction of newly qualified teacher. Journal of Education for Teaching, 27, 297.

Hobson, A. J., Ashby, P., Malderez, A., \& Tomilson, P. D. (2009). Mentoring beginning teachers: What we know and what we don't. Teaching and Teacher Education, 25, 207-216.

Richards, J. C., Li, B., \& Tang, A. (1998). Exploring pedagogical reasoning skills. In J. C. Richards (Ed.), Beyond training (pp. 86-103). Cambridge, U.K.: Cambridge University Press.

Wong, H. K. (2004, March). Induction programs that keep new teachers teaching and improving. NASSP Bulletin, 88(638), 41-58. Retrieved September 15, 2014, from http://bul.sagepub.com 